\title{
Canada's fevered failure on malaria
}

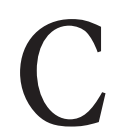
anadians pride themselves on being citizens of a humanitarian nation. But when it comes to the infectious disease that kills more African children than any other - malaria - the indolence of Canada's government is baffling and embarrassing.

Tomorrow (April 25) is Africa Malaria Day - a creation of the United Nations, which in 1998 launched a campaign to "Roll Back Malaria" (RBM) aimed at halving malaria deaths and cases by 2010. The Canadian International Development Agency (CIDA) joined that campaign, and now, with only 3 years to go in the campaign, is a good time to ask how RBM and CIDA are doing.

Epidemiologically, the news is desperate. With limited foresight, the UN set its target without a baseline measurement of cases or deaths. That leaves only epidemiological models, suggesting no reduction - and probably an increase - compared with when RBM began 9 years ago. ${ }^{1}$ By imprecise convention, an estimated I million children die annually of malaria. To imagine it, visualize 7 Boeing 747 s, packed full of children, crashing daily.

But it does not have to be this way. Malaria control is mind-bogglingly good value for money. The disease is $100 \%$ treatable with highly effective artemisinin-combination treatments costing a dollar, and nearly 100\% preventable with insecticides sprayed on house walls or impregnated into bednets, costing about $\$ 5$. There is no scientific controversy: everyone agrees these tools work. ${ }^{2}$ Together, they could staunch about $20 \%$ of child deaths and relieve health systems, where $25 \%-40 \%$ of clinic visits, and $20 \%-50 \%$ of hospital admissions, are malaria related.

Yet Canadian governments, both Liberal and Conservative, have been slow to help. Indeed, helping was for a long time unenticing, as a string of malaria program directors at WHO made technically inept choices, such as opposing DDT as an antimalarial insecticide, and recommending treatments made obsolete by drug resistance (e.g., chloroquine). Thankfully, WHO now has an able new director, Dr. Arata Kochi, who a decade ago founded WHO's successful tuberculosis program with Canadian money.

Kochi's plan is to impose a scientific stamp on malaria control. This is wise, given the current tendency to choose what is bureaucratically easy, rather that what is medically correct in managing malaria. For example, the World Bank and the Indian government disastrously wasted money and children's lives purchasing ineffective chloroquine, despite knowing drug-resistant Plasmodium falciparum malaria existed in India. WHO hopes to avoid such debacles by training technical experts in poor countries, and by wrangling agencies like the World Bank into respecting WHO policies based on clinical evidence.

So with that commendable vision, in the last year Kochi and his team made 3 pilgrimages to CIDA. They sought $\$ 50$ million annually of the roughly $\$ 4$ billion CIDA budget. Each time CIDA sent them away empty-handed.

CIDA's record on malaria is disturbing. Not only is it cool to WHO's scientific vision, but it wastes money on pseudoscience. The agency put \$I4 million into 2 projects to research and promote "home-grown antimalarial treatments," without clinical evidence that these treatments are effective. Meanwhile, for want of \$I million annually, WHO has had to shelve its plans to map malaria drug resistance, which would allow existing, highly effective treatments to be targeted to those in need.

CIDA even managed the extraordinary feat of snatching defeat from the jaws of victory when, to its credit, it once tackled malaria successfully. CIDA and the Canadian Red Cross ran a highly acclaimed project to give away free insecticideimpregnated bed-nets, which saved 75000 children's lives. But CIDA let the funding run out last year. A \$roo million proposal by the Canadian Red Cross for scaling-up languished for 18 months on CIDA's desks. It took furious pressure from journalists and Parliament to move CIDA to act, although by then, the agency's plodding timeline made approval of the full budget impossible. Thus a successful, life-saving project had to be arbitrarily cut $80 \%$, to $\$ 20$ million (not yet approved at press time, but expected soon).

The CMAJ thinks Canada could take a hint from the United States, where an alliance of right-wing think-tanks, evangelicals and professors sold George W. Bush on the US\$I.I billion President's Malaria Initiative. That program is getting rave reviews, because it transparently focuses on interventions that work in a small number of countries. Can the Conservatives also latch onto malaria and use it as a "pathfinder" to tidy CIDA's Augean stables? Time will tell, but Canadians and countless Boeing $747 \mathrm{~s}$ of African children should hope so.

\section{Amir Attaran}

Canada Research Chair in Law, Population Health and Global Development Policy

University of Ottawa

Ottawa, Ont.

For the Editorial-Writing Team (Paul C. Hébert, Matthew Stanbrook, Barbara Sibbald, Ken Flegel, Wayne Kondro and Amir Attaran)

Additional resources on this topic are available at www.cmaj.ca/cgi/content /full/176/9/1249/DCI

\section{REFERENCES}

I. Snow RW, Guerra CA, Noor AM, et al. The global distribution of clinical episodes of Plasmodium falciparum malaria. Nature 2005;434:214-7.

2. Barnes KI, Durrheim DN, Little F, et al. Effect of artemether-lumefantrine policy and improved vector control on malaria burden in KwaZulu-Natal, South Africa. PLOS Med 2005;2:e330. 